\title{
Caracterización de la oferta del crimen en Colombia 2010-2017*
}

\author{
Recibido: 14 de abril de 2020 - Aprobado: 16 de junio de 2020 \\ https://doi.org/10.22395/seec.v23n54a15 \\ Héctor Daniel Martínez Duarte** \\ Angel David Ramirez Romero ${ }^{* * *}$ \\ Eder Alexander Botello Sánchez ${ }^{* * *}$
}

\section{RESUMEN}

El crimen es un fenómeno social altamente complejo. Si bien para su comprensión se ha hecho necesario el abordaje desde diversas ciencias dada su multidimensionalidad, el enfoque ortodoxo sigue siendo una de las mejores aproximaciones al explicar el comportamiento promedio del mismo. El presente artículo tiene como fin caracterizar la oferta criminal de Colombia y sus departamentos para contribuir a una mejor comprensión. Para ello, se vale del análisis estadístico descriptivo y geoespacial de las principales variables que rodean el delito desde la teoría clásica de la economía del crimen y sus más recientes aplicaciones. Los resultados sugieren que el crimen y su comportamiento no solo ha mutado en los últimos años, sino que no es homogéneo en todo el territorio dadas las diversas condiciones de los mismos.

\section{PALABRAS CLAVE}

Crimen; violencia; delitos; territorio.

\section{CLASIFICACIÓN JEL} Al4, D74, H56, Cl6.

\section{CONTENIDO}

Introducción; 1. Marco teórico; 2. Metodología; 3. Resultados; 4. Conclusiones; Bibliografía.

- Este artículo de investigación es producto de un proyecto de aula realizado hacia finales del 2018 para la asignatura de desarrollo económico de la facultad de ciencias económicas y empresariales de la universidad de Pamplona. Los entonces estudiantes Héctor Daniel Martínez Duarte y Angel David Ramirez Romero, establecieron los lineamientos para lo que sería el trabajo de grado de Héctor Daniel Martínez Duarte.

* Economista, Universidad de Pamplona, Villa del Rosario, Colombia. Joven Investigador. Dirección: Autopista Internacional Vía Los Álamos Villa Antigua Villa del Rosario Norte de Santander. Teléfono: +57 3115372322. Correo electrónico: hector.martinez@unipamplona.edu.co. Orcid: https://orcid.org/0000-0002-4612-6974

*.. Economista, Universidad de Pamplona, Villa del Rosario, Colombia. Estudiante de maestría en economía de la Universidad de Los Andes, Bogotá, Colombia. Dirección: Autopista Internacional Vía Los Álamos Villa Antigua Villa del Rosario, Norte de Santander. Teléfono: +57 3105869341. Correo electrónico: ad.ramirezr12@uniandes. edu.co. Orcid: https://orcid.org/0000-0002-1259-2870

.... Economista, Universidad de Pamplona, Colombia. Especialista en Gerencia Financiera, Universidad Libre, Cúcuta, Colombia. Magíster en Estudios y Gestión del Desarrollo, Universidad de la Salle, Bogotá, Colombia. Profesor e investigador del grupo de Investigación Economía y Estudios Fronterizos (Ecoesfront) de la Universidad de Pamplona, Villa del Rosario, Colombia. Dirección: Autopista Internacional Vía Los Álamos Villa Antigua Villa del Rosario, Norte de Santander. Teléfono: +57 3123285008 . Correo electrónico: alexander.botello@unipamplona. edu.co. Orcid: https://orcid.org/0000-0003-4363-5551 


\title{
Characterization of the Offer of the Crime in Colombia 2010-2017
}

\begin{abstract}
Crime is a highly complex social phenomenon. Even though crime is a highly complex social phenomenon. Even though a diverse approach from multiple sciences has been necessary for its comprehension, the orthodox approach remains as one of the best approaches for explaining the medium behaviour of the phenomenon. This article's purpose is to characterise the criminal offer in Colombia and its regions for a better understanding of it. For that, this article counts with geo-spatial and descriptive statistic analysis of the main variables around felonies from the classic crime economy theory and its most recent applications. The results suggest that crime and its behaviour have not only mutated in these recent years but that it is not homogenous in the whole territory given the diverse conditions of these.
\end{abstract}

\section{KEY WORDS}

Crime; violence; felonies; territory.

\section{JEL CLASSIFICATION}

A14, D74, H56, C16.

\section{CONTENT}

Introduction; 1. Theoretical framework; 2. Methodology; 3. Results; 4. Conclusions; Bibliography.

\section{Caracterização da oferta criminal na Colômbia 2010-2017}

\section{RESUMO}

O crime é um fenômeno altamente complexo. Embora, para sua compreensão, é necessário abordá-lo a partir de diversas ciências, devido à sua multidimensionalidade, a abordagem ortodoxa continua sendo uma das melhores aproximações ao explicar o seu comportamento padrão. Este artigo tem o objetivo de caracterizar a oferta criminal da Colômbia e de seus estados para contribuir para uma melhor compreensão do tema. Para isso, utiliza a análise estatística descritiva e geoespacial das principais variáveis que estão em torno do delito sob a teoria clássica da economia do crime e suas mais recentes aplicações. Os resultados sugerem que o crime e seu comportamento não somente tenham se transformado nos últimos anos, mas também que não sejam homogêneos em todo o território, tendo em vista suas diversas condições.

\section{PALAVRAS-CHAVE}

Crime; violência; delitos; território.

\section{CLASSIFICAÇÃO DE JEL}

$$
\text { A14, D74, H56, C16. }
$$

\section{CONTEÚDO}

Introdução; 1. Referencial teórico; 2. Metodologia; 3. Resultados; 4. Conclusões; Bibliografia. 


\section{INTRODUCCIÓN}

El crimen es un asunto que preocupa tanto a ciudadanos como a gobernantes. Los daños colaterales que este produce se pueden analizar y evaluar desde distintas perspectivas. Por tanto, es materia de la intervención del Estado, "en donde la medición de la criminalidad y de las acciones emprendidas para disminuirla presenta un grado de complejidad particularmente alto" (Tamayo y Norza, 2018, p. 51). No obstante, autores como Rubio (1995), Becker (1968) y Buvinic, Morrison y Orlando (2005) han demostrado el costo o pérdida social que el crimen produce, el gasto público que consume y el impacto a nivel microeconómico y macroeconómico en las economías. En este sentido, Fajnzylber, Lederman, y Loayza (2001) afirman: "La preocupación por el crimen está bien justificada dados sus perniciosos efectos sobre la actividad económica y la calidad de vida de las personas, que deben sostenerse con un reducido sentido de seguridad individual y de sus propiedades" (p. 4).

Por lo anterior, el estudio del crimen ha sido abordado desde múltiples disciplinas y enfoques, atraviesa campos éticos y filosóficos, y llega a disciplinas como la sociología, la psicología y la economía actualmente. Esto ha permitido ampliar el conocimiento sobre las diversas variables que influyen en los hechos que envuelven al crimen para ser entendido, finalmente, como un fenómeno que evoluciona en conjunto con el desenvolvimiento de la sociedad en sí misma (Becaria, 1821).

Tras el abordaje mencionado, los conceptos y definiciones alrededor del crimen no son homogéneos. Para este caso, es válido señalar que el crimen es un concepto multicausal que se compone por diversas variables, las cuales son tan particulares que la oferta criminal de un territorio es caracterizada por las condiciones sociales, económicas, institucionales y geográficas que el mismo aporta. Por lo tanto, aunque el crimen ha sido abordado a partir de enfoques interdisciplinarios, la perspectiva clásica de la economía del crimen provee un aproximación significativa. Este enfoque es adaptado en el presente artículo desde la economía ortodoxa, pero también se tienen en cuenta las variables proxy multidimensionales para realizar un análisis más completo que permita dilucidar las posibles relaciones entre la oferta criminal y el territorio.

Un ejemplo de la complejidad del crimen son los diversos resultados en la tasa de homicidios que se presentan en Latinoamérica en cada región, teniendo en cuenta su amplia geografía, toda vez que América Central y el Caribe inflan el promedio latinoamericano frente al sur (zona más pacifica) que posiciona la región como una de las zonas más violentas del mundo (CC News, 2019). Según Jaitman et al. (2017), América Latina ha logrado avanzar en muchas áreas socioeconómicas. Sin embargo, en materia de crimen tiene largo camino por recorrer. Un caso similar es Colombia 
que, como lo señala Robinson y Urrutia (2007), ha experimentado incrementos en PIB per cápita, escolaridad y rápida urbanización. Sin embargo, el Estado no ha logrado establecer el monopolio de la fuerza en todo el territorio.

Tanto Colombia como los demás países afectados por el crimen en América Latina presentan características comunes. Jaitman et al. (2017) argumentan que el sistema judicial es ineficiente y no alcanza a resolver el $10 \%$ de los delitos cometidos en el caso colombiano. Collazos et al. (2020) muestran que Colombia es un estudio de caso ideal, dado el pobre desempeño de las investigaciones de homicidio en el país con muy bajas tasas de acusación e imputación de cargos. Adicionalmente, el narcotráfico hace mella en las cifras de seguridad de toda la región. En este sentido, Chabat (2010) argumenta que:

En América Latina destacan los cárteles de la droga mexicanos, los cuales se han modificado y recompuesto en los últimos años. Varias de estas organizaciones criminales tienen presencia en el resto de Latinoamérica y han hecho alianzas con otros grupos criminales en Colombia y Europa para la distribución de drogas. En América Latina subsisten los cárteles colombianos, los cuales, si bien se han atomizado, siguen produciendo la mayor cantidad de cocaína que circula en el mundo, así como algunas mafias desarrolladas en las rutas de la droga hacia el mercado estadounidense, tales como los "yardees" jamaiquinos. (p. 7)

En el contexto nacional se han logrado avances en la lucha contra los grupos armados, así como en las soluciones dialogadas para poner fin a los conflictos y la violencia. Esto se vio reflejado en el Acuerdo de Santa Fe Ralito en 2005 y el acuerdo de paz con una de las guerrillas más importantes de su historia en 2016. Lo anterior dio paso a una mayor visibilidad y atención por parte del Estado frente al crimen organizado, ya que el conflicto ideológico había terminado.

Tal como señala Hernández (2016), "quedan desafíos enormes como la delincuencia organizada, las bacrim, la inseguridad urbana y rural y sobre todo la rampante corrupción de la política, la justicia y la policía" (p. 23). Así las cosas, la violencia parece reinventarse a través las economías ilegales que la permiten. Esto se evidencia con el surgimiento de grupos armados ilegales o bacrim que se dieron luego de la desmovilización paramilitar en 2005. Según Ávila (2019), para el año 2012, "de los más de 100 grupos que surgieron de esta desmovilización se contabilizaban 7 grandes estructuras" (p. 473). Estas modificaron sus modus operandi mediante tres transformaciones: la subcontratación criminal, la autonomía criminal y los homicidios ejemplarizantes.

Actualmente, tras el fin del conflicto con las FARC, los indicadores de seguridad se han vuelto a deteriorar, pero no se comparan con la década pasada. Ávila (2019) 
argumenta que, tras la desmovilización, los grupos armados ilegales han llenado los territorios donde operaron las FARC, conocidos como las zonas del postconflicto, las cuales se han visto más vulnerables ante dicha situación. Este problema podría calificarse como previsible, ya que una de las problemáticas estructurales del Estado colombiano y un objetivo de los acuerdos de paz es tener el monopolio del uso de la fuerza en todo el territorio.

A pesar del repertorio paz, descentralización e intervención nacional, Colombia sigue siendo el país con mayor presencia diferenciada del Estado a lo largo de su territorio de toda América, y con un oligopolio endémico de agentes de coerción privada que desafían eficazmente el monopolio estatal. (López, 2016, p. 25)

Así pues, aunque el crimen se presente a nivel nacional, son evidentes las desigualdades que interfieren en el desarrollo de este. Por consiguiente, es importante ahondar en los diferentes espacios geográficos del país, donde son más evidentes las desigualdades económicas y sociales. En este sentido, López (2016) plantea tres colombias como resultado de un sistema político desigual: "una urbana institucionalizada e integrada, una Colombia semiurbana y semiintegrada y una tercera rural, pobre, básicamente sin Estado y muy desintegrada del resto del país" (p. 13).

Lo anterior ha sido catalogado como una de las problemáticas que pueden provocar violencia y crimen, como lo sugiere parte de la literatura de la escuela neoinstitucional del desarrollo. Las condiciones de los territorios y vida de los habitantes permiten indagar sobre la clase de relaciones sociales entre los mismos, más en el caso colombiano, en donde los problemas de violencia han sido mayormente explicados por la debilidad del Estado que por las drogas (Holmes y Gutiérrez, 2014). En este contexto, el presente artículo se propone caracterizar ampliamente la oferta criminal y contribuir a futuros estudios y análisis de costos, causas y factores disuasores del crimen.

Finalmente, el presente documento abarca el periodo de tiempo 2010-2017, en donde las cifras de crimen y violencia aumentaron durante una parte de ese intervalo y luego disminuyeron, es decir, antes y después del acuerdo de paz con la guerrilla de las FARC. Para ello, el texto se divide en cinco secciones: primero esta introducción seguida por el marco teórico, la tercera sección aborda la metodología, la cuarta los resultados y, por último, las conclusiones.

\section{ENFOQUE TEÓRICO}

La historia del crimen puede verse iniciada en el siglo de las luces, pues este ha estado ligado a la conformación de las leyes que permitieron la cimentación del 
Estado contemporáneo. Esos principios de la Ilustración como la optimización cultural, el racionalismo y los derechos humanos permitieron abordar distintos fenómenos sociales. De esta manera, se dejó de la do la efera religiosa y se le dio valor al individuos al punto que se luchó en contra de la esclavitud y a favor del trato humano con los delincuentes.

En consecuencia, Becaria (1764) definiría ese Estado como pactos considerables de hombres libres, los cuales estarían cada vez más propensos a ser incumplidos en proporción a la manera en que la sociedad fuera evolucionando. Diversos autores han abordado esta temática desde inicios del siglo XIX, también desde variados enfoques y la interdisciplinariedad, la cual ha permitido que en la actualidad se identifiquen de mejor manera sus causas, comportamiento y consecuencias. Anzola et al. (2005) exponen que, desde los inicios la psicología, se marcó una pauta en la forma en que se entendía el delito, ya no como una expresión despreciable de la humanidad, sino como una de las actividades cotidianas de los seres humanos a las cuales las autoridades debían hacerle frente. También se pudo observar un aporte de la sociología en cuanto a la caracterización del perfil del reo como, por ejemplo, su educación, edad, género, etc.

Según Ehrlich (1996), la economía se interesó por este tema en la misma época, desde Smith, pasando por William Petty, hasta Jeremy Betham. En este sentido, respondió preguntas como las siguientes: ¿De dónde proviene la demanda de protección contra el crimen? ¿Cuáles son las magnitudes reales de severidad de las sanciones? ¿Cuál es el óptimo de respuesta que deben tener las autoridades frente al crimen?

La búsqueda por responder a la pregunta de la violencia inherente al crimen se ha estudiado desde diversas disciplinas que tratan de comprender el comportamiento humano. Al hablar de oferta criminal, se remite a los elementos que componen un concepto economicista en el marco de una ciencia que puede contemplar la seguridad como un bien y que, en llegados casos, el disfrute de ese bien puede estar truncado por esa oferta laboral análoga a la oferta de personas disponibles hacia las actividades delictivas.

Recientemente, el estudio del crimen desde el enfoque económico casi siempre se remite a su mayor exponente del siglo XX: Becker (1968). Este autor plantea que los criminales son agentes racionales y sus conductas responden al beneficio personal versus el riesgo. En este sentido, afirma Gaviria (2001): "Esta perspectiva, al comienzo polémica, se ha convertido en un lugar común dentro de la literatura económica. El modelo de Becker predice que los criminales expandirán sus actividades si la certeza o la dimensión del castigo disminuyen" (p. 164). 
Más adelante surgieron aproximaciones que tenían en cuenta otras variables alrededor del crimen y no la sola racionalización de la acción. Según Sánchez y Núñez (2001):

En los años recientes han sido dos las tendencias principales: la primera, que podríamos llamar la hipótesis de las causas objetivas, explica la violencia como el resultado, entre otros, de la pobreza, la exclusión, la falta de presencia del Estado, la escasa provisión de servicios sociales y la desigualdad de ingresos o de activos. La segunda tendencia parte de la teoría económica sobre la conducta criminal basada originalmente en los trabajos de Becker (1968) que desarrollan una teoría económica del crimen y los de Ehrlich que aportaron evidencia empírica creando el llamado modelo de mercado de ofensas. (p. 92)

El modelo de Ehrlich (1996), al igual que el de Becker (1968), proviene de la tradición neoclásica con supuestos como los siguientes: los individuos de mercados ilegales y sus contrapartes se rigen bajo las reglas de la optimización. Asimismo, estos individuos tienen expectativas dependiendo de la gravedad o certeza de castigo, es decir, una distribución estable de las preferencias por el delito, así como por la seguridad frente al delito entre la población. Por último, la ley tiene como objetivo final la maximización del bienestar social.

En este sentido, Ehrlich (1996) argumenta que el nivel del crimen está determinado conjuntamente por la oferta de delitos (que refleja las decisiones de la gente de participar en actividades ilegales), y la demanda de protección privada y pública contra el crimen (lo cual define implícitamente la demanda de delitos). (Gaviria, 2001, p. 164)

Así las cosas, estos modelos se han puesto en duda a la hora de estudiar el crimen en Colombia. Por su naturaleza, no deberían existir prolongados auges en las cifras que engloban el crimen, como se han visto para el caso colombiano. Según Sánchez y Núñez (2001), entre la literatura colombiana más importante a la hora de explicar la violencia se encuentran los trabajos de Sarmiento (1999). Este encuentra que la violencia está asociada negativamente con los niveles de educación, participación política y positivamente con el nivel de riqueza, y principalmente con la inequidad medida a través del coeficiente de Gini. De igual manera, el trabajo de Moser (1999) propone tres tipos de violencia en Colombia: política, económica y social. El autor considera que en las causas de cada uno de esos tipos de violencia se encuentran las instituciones corruptas, una sociedad con bajos niveles de tolerancia y normalización de la violencia para la solución de problemas, fragmentación económica y la descentralización en zonas con poca presencia estatal.

Esta última variable prima de igual manera para el trabajo de López y García (1999) quien argumenta que, más que la pobreza, la desigualdad es la causa de la 
violencia. En este sentido, esta se propaga más rápidamente donde el Estado no tiene el monopolio de la fuerza. Contrario al enfoque de las causas por falta de necesidades satisfechas, repunta lo dicho por Rubio (1999), quien infiere que no es favorable pensar en la violencia como un acto generado por individuos presionados a delinquir por sus necesidades insatisfechas. En este contexto, Sánchez y Núñez (2001) afirman que "las mayores tasas de criminalidad están presentes en las ciudades más desarrolladas a manos de individuos con mayor acceso a la educación y al empleo, y en los municipios donde confluyen las organizaciones ilegales armadas, (guerrilla, paramilitares, narcotráfico)" (p. 95).

Tras el análisis anterior, la eficiencia judicial se pone a prueba como reproductora del crimen. Echeverry y Partow (1998) explican en su trabajo cómo la baja respuesta del sistema policivo y judicial explican las altas tasas de violencia en el país, en parte porque el narcotráfico incrementó las tasas de homicidios en Colombia. Sin embargo, la respuesta policial no se dio, pues se consideraba un fenómeno global no originario de las respectivas jurisdicciones policiales y judiciales. En este sentido, Sánchez y Núñez (2001) afirman:

De acuerdo con los autores, dada la naturaleza descentralizada de la toma de decisiones por parte de las autoridades policivas y judiciales, la respuesta de las autoridades ante un choque que aumente la tasa de crimen depende de la percepción que estas tengan del origen del choque. (p. 96)

Como resultado se obtiene un grupo heterogéneo de explicaciones que, aunque han logrado amplios avances en el estudio de la criminalidad, aún hacen falta estudios más amplios sobre sus causas. Como lo menciona Iglesias Estepa (2005),

(...) las causas y la incidencia del crimen no pueden explicarse atendiendo a la influencia de un único factor, sino que dependen de la conjunción de los efectos de un amplio conjunto de variables económicas, sociales, políticas, institucionales, culturales, mentales etc., de ahí que la explicación de los cambios en las tasas de delincuencia y en la relación interna de las categorías delictivas pase por la formulación de teorías globalizantes. (p. 305)

Asimismo, de acuerdo con el planteamiento de Ramírez de Garay (2014), las explicaciones criminales se ven altamente correlacionadas con los factores sociales que crean el escenario para que se finiquiten los actos. Por lo tanto, desde el enfoque del ciclo económico o del desarrollo económico, la relación se ve caracterizada por tres tipos de problemas: inicialmente surge una relación directa que tiene una difusa causalidad; en segundo lugar, se desconocen los móviles individuales que incentivan el crimen; por último, toda vez que los estudios son precarios y parciales, 
las conclusiones son acertadas en términos generales, pero sesgadas en lo que respecta a casos particulares. No obstante, hasta hoy día, "la teoría clásica-racional, con algunos de sus puntos débiles, sigue siendo la mejor aproximación para el cumplimiento de la ley y el orden" (Garoupa, 2003, p. 12).

De modo que, en términos agregados, el comportamiento del crimen desde la perspectiva teórica se debe en gran medida a la relación multidimensional que interactúa dinámica y particularmente en un territorio. En otras palabras, propone que las convicciones y motivaciones individuales que incentivan el crimen se deben a cuestiones normativas, estructurales y contextuales. Estos factores influyen en la población al punto de fijar el volumen de actos criminales que se cometen en el territorio durante un periodo de tiempo específico.

\section{METODOLOGÍA}

La presente investigación se realiza a partir de la estadística descriptiva o análisis exploratorio. Según Orellana (2001), estos métodos ayudan a presentar los datos de modo que sobresalga su estructura. Lo anterior permite identificar de manera preliminar las características de variables que se pueden poner a prueba en estudios e hipótesis que se desarrollen más adelante. Ahora bien, la caracterización de las variables parte de la estadística descriptiva y la georreferenciación, prosigue con correlaciones y culmina con series de tiempo.

Como se mencionó en el enfoque teórico, las actividades delictivas en las que se refleja la oferta criminal se han diversificado y aumentado con la sofisticación de las sociedades, como se ve en el área de los impuestos, multas, etc. Por lo tanto, el presente artículo hace referencia a la oferta criminal, es decir, a los delitos más graves según las investigaciones que se ha hecho en los últimos cincuenta años, como lo son los homicidios, el hurto y los delitos sexuales. Así, los autores buscan caracterizar las principales variables que se deben tener en cuenta en futuros trabajos que estudien las causas, los costos y los factores de disuasión del crimen. De igual forma, a manera de orientación se plantea la hipótesis de que el crimen en Colombia es heterogéneo y su comportamiento depende de las características del territorio.

Finalmente, se recurre al cálculo de estadísticos de medida de tendencia central, el intervalo en el que oscila la variable y los estadísticos para determinar si la variable se comporta bajo distribución normal. Asimismo, se analiza la concentración tanto de los delitos como de otras variables que representan la oferta de seguridad desde el punto de vista operativo y logístico de la institucionalidad (dotación policial, capturas), económico (PIB per cápita, PIB departamental), demográfico (densidad 
y edad) y geográfico (área y localización del territorio). Así, con el fin de incluir el análisis temporal en el estudio, se recurre al uso de gráficos de corte longitudinal. Se recurrió a la selección de la información relevante recopilada y organizada por el Departamento Administrativo Nacional de Estadística (DANE) en la cuentas anuales departamentales y la gran encuesta integrada de hogares y proyecciones demográficas, donde se expone a detalle la mayor parte de las variables necesarias. Por otra parte, la base de datos TerriData del Departamento Nacional de Planeación y del Observatorio del Delito de la Policía Nacional complementaron el estudio.

\section{RESULTADOS}

Inicialmente cabe aclarar que teniendo en cuenta el número de variables y que el panel de datos adoptado cuenta con 2.304 datos, se hace necesario resumir la información de manera que permita prever el comportamiento de las variables de la manera más intuitiva, gráfica y analítica. A continuación, se exponen las medidas de tendencia central, presentando las generalidades descriptivas de las variables recopiladas, cuya información obtenida se resume en la tabla 1.

\subsection{Análisis desde la perspectiva de la estadística descriptiva}

Tabla 1. Resumen de los estadísticos descriptivos

\begin{tabular}{ccccccc}
\hline \multirow{2}{*}{ Variables } & \multicolumn{5}{c}{ Estadísticos descriptivos } \\
\cline { 2 - 7 } & \multicolumn{2}{c}{ Tendencia central } & \multicolumn{2}{c}{$\begin{array}{c}\text { Medidas de precisión } \\
\text { probabilística }\end{array}$} & $\begin{array}{c}\text { Medida de } \\
\text { oscilación }\end{array}$ \\
\cline { 2 - 7 } & Media & Mediana & Error estándar & Asimetría & Curtosis & Rango \\
\hline Área & 35,68 & 24,35 & 28,48 & 1,12 & 3,37 & 108,08 \\
\hline Región & 0,53 & 1,00 & 0,50 & $-0,13$ & 1,02 & 1,00 \\
\hline Crímenes Totales & $5.572,71$ & $3.199,50$ & $8.548,78$ & 3,38 & 15,97 & $58.929,00$ \\
\hline Gran Ciudad & 0,38 & - & 0,49 & 0,52 & 1,27 & 1,00 \\
\hline Densidad Poblacional & $233.891,60$ & $54.703,89$ & $844.682,10$ & 5,20 & 28,69 & $5.091 .299,42$ \\
\hline Dotación Policial & $20.452,78$ & $10.487,47$ & $33.353,64$ & 3,31 & 14,32 & $179.217,95$ \\
\hline Ruralidad & 0,52 & 1,00 & 0,50 & 0,06 & 1,00 & 1,00 \\
\hline Frontera & 0,38 & - & 0,49 & 0,52 & 1,27 & 1,00 \\
\hline Ingreso Corriente Legal & $413.449,70$ & $424.670,80$ & $193.305,30$ & 0,29 & 1,95 & $711.738,40$ \\
\hline Ingreso Corriente ilegal & $12.662,966$. & $10.078,119$ & 8.249 .554 & 1,91 & 6,78 & 41.506 .947 \\
\hline Pib Corriente & $23.503,34$ & $12.096,94$ & $38.575,67$ & 3,34 & 14,68 & $218.433,92$ \\
\hline
\end{tabular}

Fuente: elaboración propia con datos de ODPN (2017a), DANE (2017), DNP (2017). 
Según la tabla 1 se puede identificar que el área promedio de un departamento administrativo en Colombia es de $35.680 \mathrm{~km}^{2}$. Asimismo, en cualquier parte del territorio nacional es de esperarse que se encuentren alrededor de 23.389 habitantes por cada $10 \mathrm{~km}^{2}$. Se tiene que el $38 \%$ de los departamentos del país tienen dentro de su territorio un área geográfica que colinda con otro país. Asimismo, los datos arrojan que el 52 \% de los territorios administrativos tienen una población inferior a la mediana, lo cual se traduce en que uno de cada dos departamentos está bajo hacinamiento relativo.

En lo que respecta a la demografía, la información suministrada indica que la distribución de la población en cuanto a género tiende a ser equitativa. Por ello, en promedio uno de cada dos habitantes de cualquier departamento durante el periodo analizado es hombre. De manera análoga, cerca del $30 \%$ de la población se halla entre diez y veinticuatro años, es decir, tres de cada diez habitantes entre 2010 y 2017 se encontraban en el rango de edad que comprende la etapa de niñez a adulto-joven. Asimismo, el PIB per cápita de los departamentos del país durante el periodo osciló entre 4,4 millones y 20,9 millones de pesos en el $95 \%$ de los casos. El comportamiento leptocúrtico de la serie expone la existencia de una brecha marcada de riqueza entre los departamentos. Complementariamente, en lo relacionado con lo institucional, el número de agentes policiales promedio por departamento es de 20.452 activos. Asimismo, con el fin de identificar la distribución de las variables, se presentan los gráficos de tipo Q (gráficos 1, 2 y 3). A continuación, en la tabla 2 se expone el resumen estadístico:

Tabla 2. Resumen de los estadísticos descriptivos, distribución normal

\begin{tabular}{ccc}
\hline Variables & Estadístico Jarque-Bera & Probabilidad \\
\hline Área & 55,41 & 0,00 \\
\hline Crímenes totales & $2.282,46$ & 0,00 \\
\hline Densidad poblacional & $8.194,28$ & 0,00 \\
\hline Dotación policial & $1.833,62$ & 0,00 \\
\hline Frontera & 43,43 & 0,00 \\
\hline Gran ciudad & 43,43 & 0,00 \\
\hline Ingreso corriente ilegal & 308,46 & 0,00 \\
\hline PIB corriente & $1.929,74$ & 0,00 \\
\hline Región & 42,67 & 0,00 \\
\hline Ruralidad & 42,67 & 0,00 \\
\hline Tasa etariedad & 59,70 & 0,00
\end{tabular}

Fuente: elaboración propia. 
De la tabla anterior se puede intuir que ninguna de las variables abordadas en el presente estudio presenta un comportamiento consistente desde el punto de vista estadístico, de modo que la distribución poblacional de las variables se enfrenta a disimilitudes altamente marcadas entre los departamentos.

Teniendo en cuenta la información suministrada por el gráfico 1, se puede identificar que el comportamiento de la serie difiere del valor esperado bajo distribución normal. De esta manera, se sugiere que el comportamiento del número de crímenes en el país no se comporta normalmente, es decir, aunque es una variable significativa, su media no es representativa debido a las diversas desigualdades a lo largo del territorio.

\section{Gráfico 1. Gráfico 0 para crímenes totales}

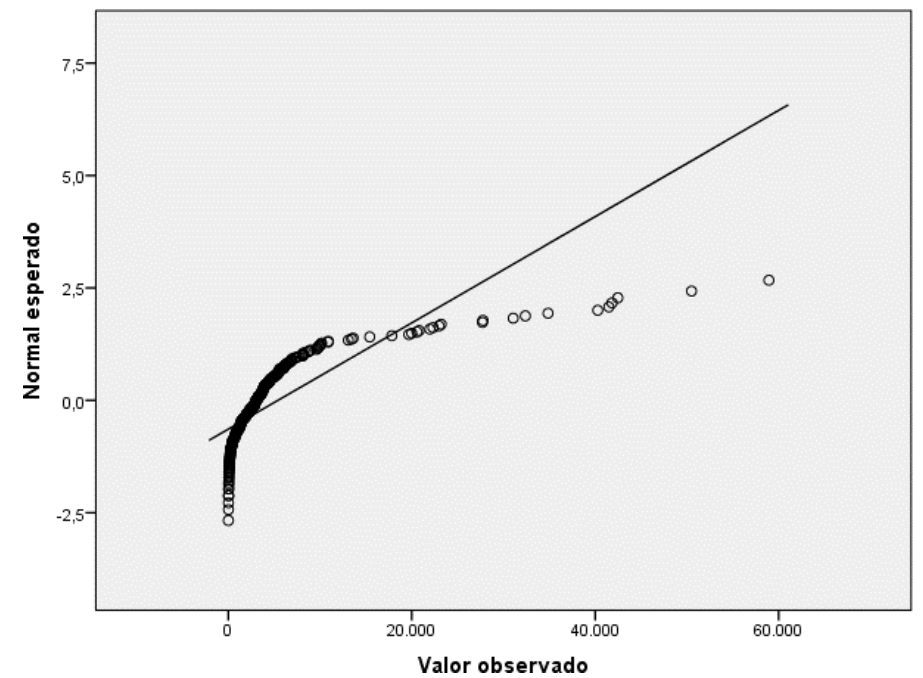

Fuente: elaboración propia basada en el Observatorio del Delito de la Policía Nacional (2017a).

Por otra parte, se tiene que el comportamiento de la variable es más verosímil a la distribución normal en lo que respecta a las capturas efectuadas en los departamentos (gráfico 2). Esto se debe a que el valor esperado y el observado interactúan de manera muy similar. Frente a esto, una posible explicación recae en la relación rezagada entre el crimen y la efectividad de los actos policiales, los cuales se distribuyen proporcionalmente dependiendo de la variación simultanea de la otra. Por ello, el promedio es una medida representativa en cada uno de los territorios. 


\section{Gráfico 2. Gráfico 0. Números de capturas por departamento}

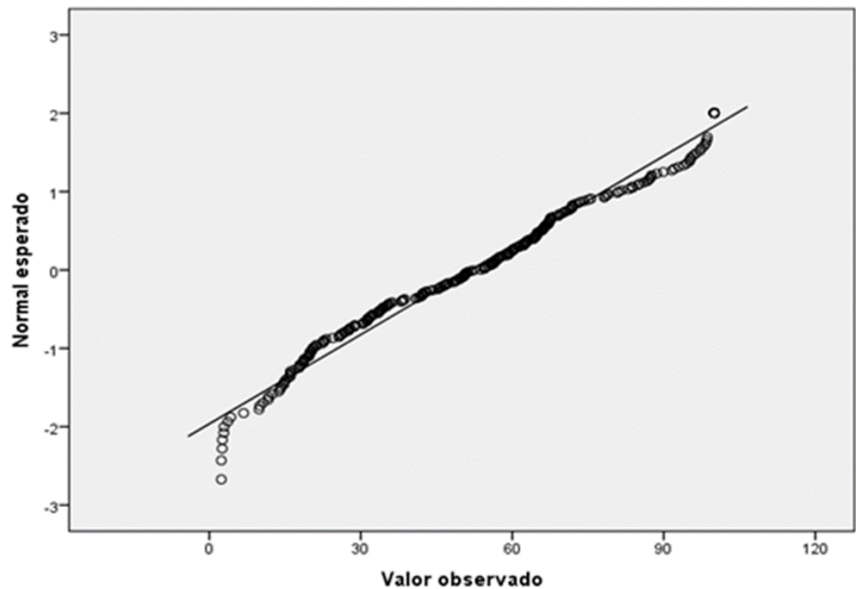

Fuente: elaboración propia basada en el Observatorio del Delito de la Policía Nacional (2017 b).

Finalmente, el contraste entre el valor normal esperado y el efectivo de la serie dotación policial revela que existe una brecha marcada entre los dos. Por ello, se puede intuir de manera visual (gráfico 3) que la variable experimenta un comportamiento que difiere de la distribución normal. Se hace importante exponer al lector que posteriormente se va a presentar únicamente la información más relevante con el fin de esbozar, grosso modo, el comportamiento y características de las variables.

Gráfico 3. Gráfico 0. Dotación policial (número de agentes)

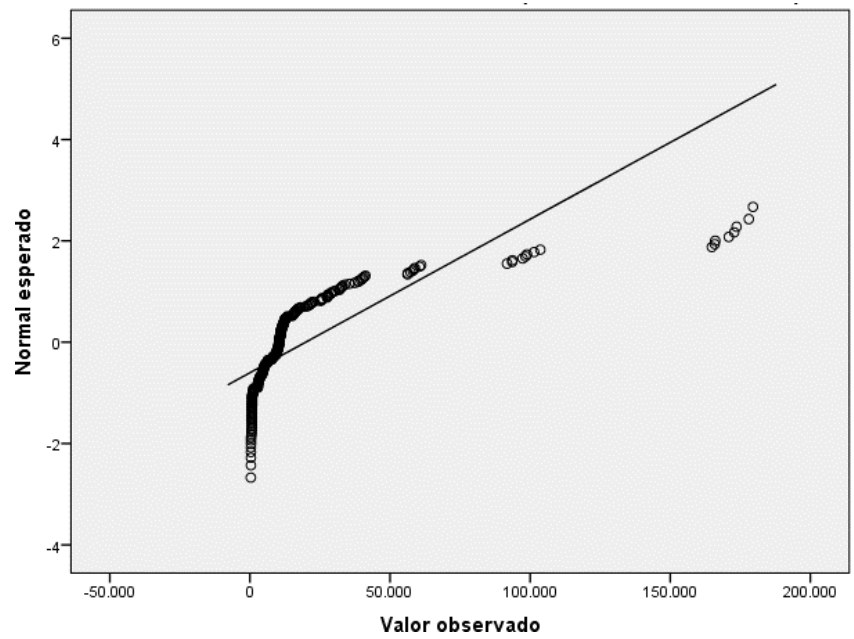

Fuente: elaboración propia basada en el Observatorio del Delito de la Policía Nacional (2017c). 


\subsection{Análisis grafico estático y contribuciones}

Partiendo de Bandrés y Diez (2001), en donde señalan que el crimen actúa de forma diferenciada entre las ciudades y el impacto de las variables disuasivas, provoca efectos disímiles. La georreferenciación se hace útil para el presente estudio dado que los resultados demuestran que las variables no se comportan normalmente. El resultado de esto, el no incluir el factor territorio (geografía), implica un sesgo analítico de tipo 1 (gráfico 4).

Gráfico 4. Capturas en el 2017

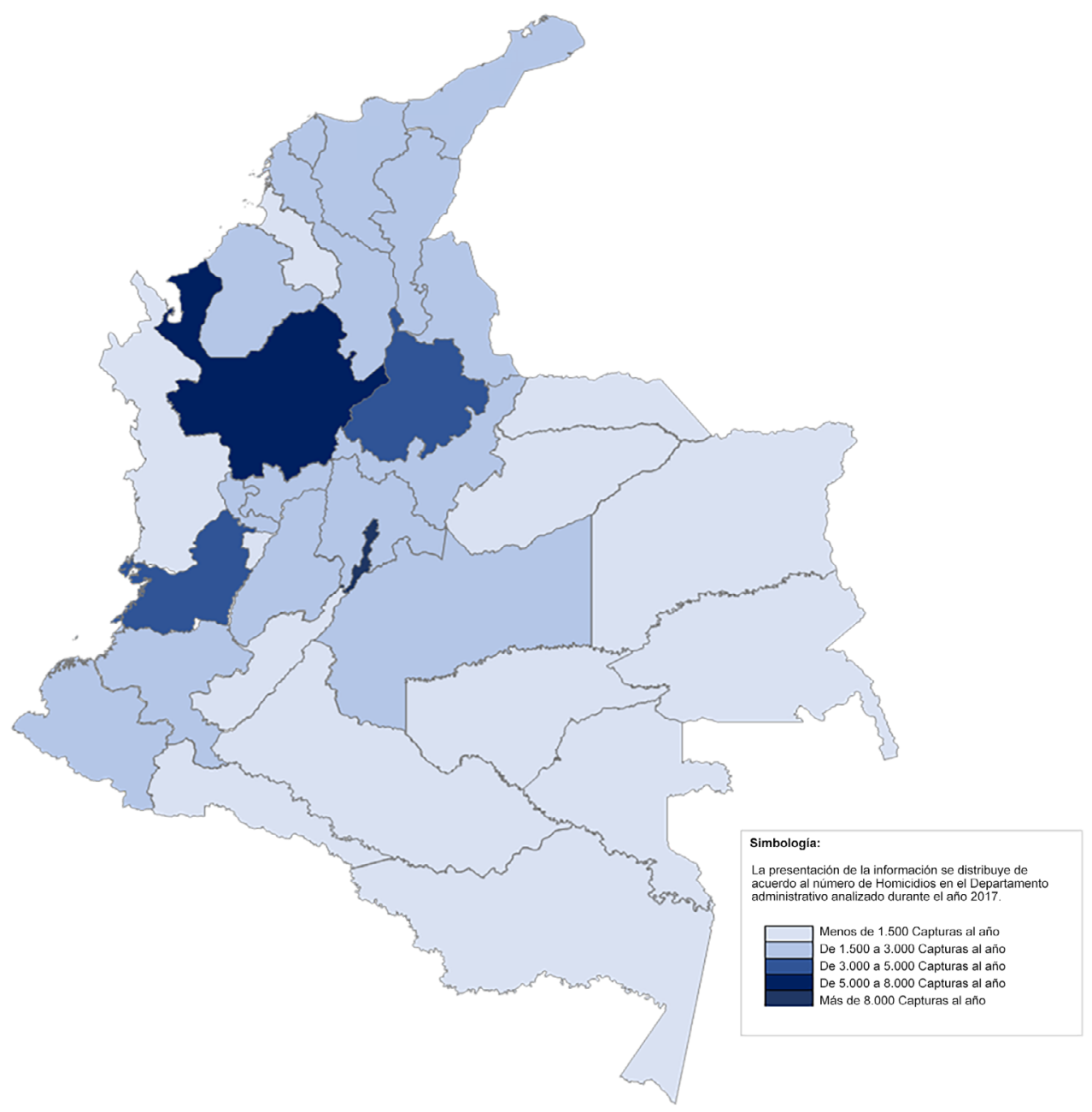

Fuente: elaboración propia basada en el Observatorio del Delito de la Policía Nacional (2017b). 
Ahora bien, para el caso de las capturas fueron más de setenta y ocho mil en el año 2017. El 57,3 \% se concentró en los seis principales departamentos del país sincrónicamente. Más del 50 \% se aglomeró en Santa Fe de Bogotá. Además, se puede vislumbrar un patrón de georreferencia en donde se concentra la efectividad policial en la región Caribe y Andina del país. En este sentido, la evidencia empírica parece seguir la validez de la premisa de Becker (1968) en donde mayores incentivos económicos propician escenarios más adecuados para la propagación de los actos criminales (gráfico 4). Asimismo, Ehrlich (1975) menciona que existe una relación endógena de causalidad en doble sentido entre el crimen y las condiciones sociales y materiales de los individuos.

A partir del gráfico 5, se presenta la concentración georreferenciada de los homicidios en Colombia. Valle del Cauca, Cundinamarca, Antioquia, Cauca y Bogotá concentran el 53,49 \% de los homicidios. Entre los casos más representativos, el primer lugar le corresponde a Valle del Cauca al cual se le atribuyen uno de cada cinco homicidios, seguido de Antioquia en donde se desarrollan quince de cada cien de homicidios en el país. Además, los datos sugieren que la distribución criminal en Colombia se concentra en la región Andina, la cual presenta 33,64 más casos que la región amazónica; 56,38 más que la región de la Orinoquía; tres homicidios por cada homicidio reportado en la región Caribe y un 63 \% más que los departamentos que colindan con el océano Pacífico. Esta tendencia no ha cambiado desde la década del 2000 (Mancera, 2010). La mayor participación de los homicidios en Colombia proviene de la región Andina y la región Caribe. Estos resultados diversos se pueden analizar a la luz de Rodríguez (2003), quien señala que los individuos que interactúan y se desenvuelven en determinada región cuentan con una serie de particularidades que establecen, en conjunto, el número de delitos que se finiquitan en dicho territorio.

En cuanto a los delitos sexuales, en el gráfico 6 se resume la información suministrada por el Observatorio del Delito de la Policía Nacional, la cual presenta una alta concentración de delitos sexuales en los principales centros de desarrollo económico y los departamentos aledaños a los mismos. Entre las actividades criminales más representativas se destaca el acceso carnal violento (49,33\% de los casos totales reportados), acoso sexual (22,64 \%) y pornografía infantil (7,82 \%). Concretamente, Antioquia presenta dos casos de delitos sexuales de cada siete denuncias en el país o el distrito capital, el cual aglomera el 15,20 \% de los casos procesados durante todo 2017. Estas cifras han cambiado en comparación con la década del 2000, pues los delitos como la violación se presentaban en mayor medida en la Orinoquía y la Amazonía (Mancera, 2010). Estos cambios serán preguntas importantes en los estudios futuros, ya que conocer si esto se debe a una mutación de los hechos o de las denuncias no es un asunto sencillo. 
Gráfico 5. Homicidios en el 2017

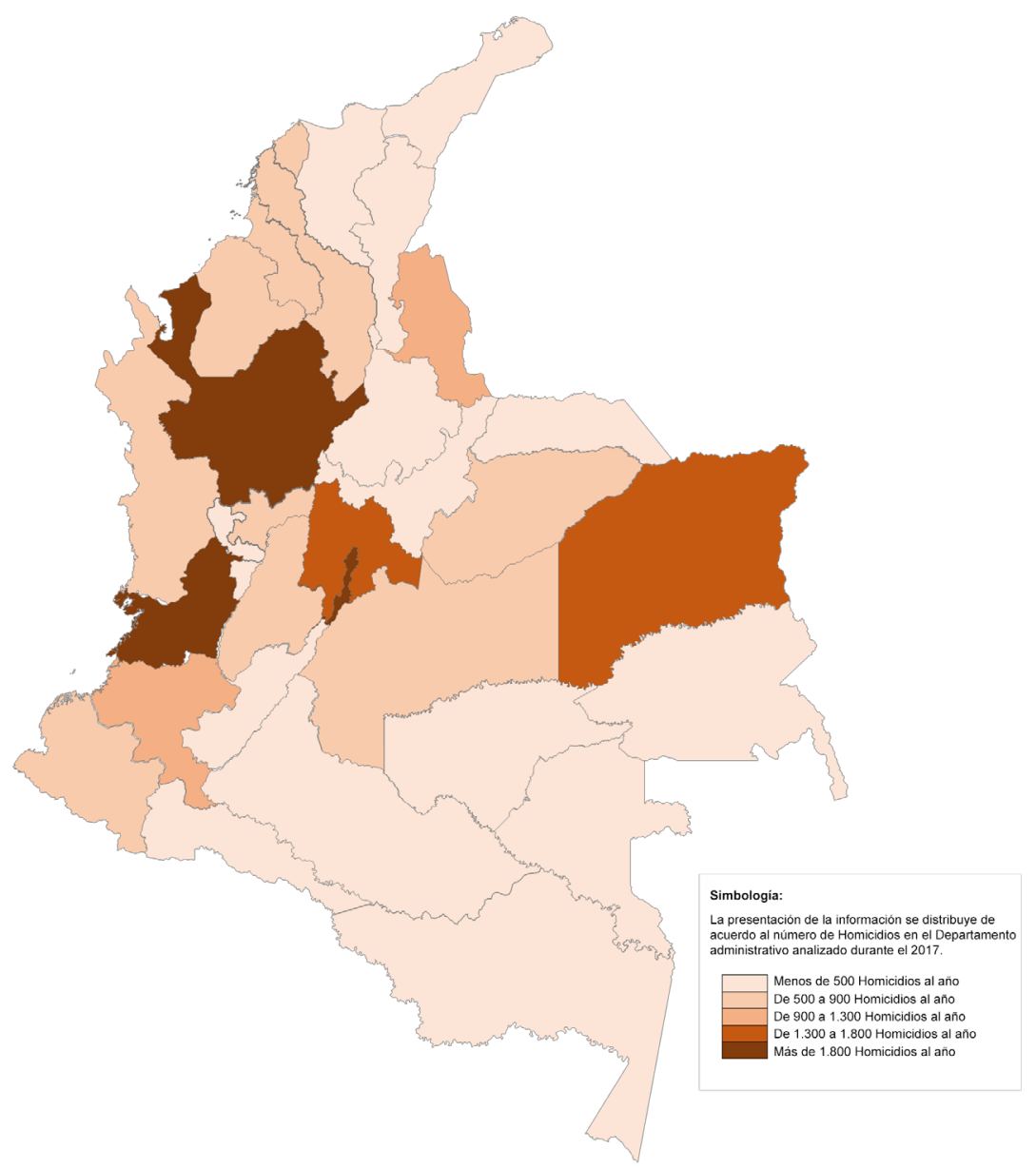

Fuente: elaboración propia basada en el Observatorio del Delito de la Policía Nacional (2017b).

La medición de la criminalidad presenta diversos retos que ni siquiera pueden enfrentarse a través del aumento de la capacidad institucional de recoger información, pues siempre existen delitos que escapan al lente institucional, sea por falta de denuncia o por simple desconocimiento de los hechos (Tamayo y Norza, 2018, p. 51). 
Gráfico 6. Delitos sexuales en el 2017

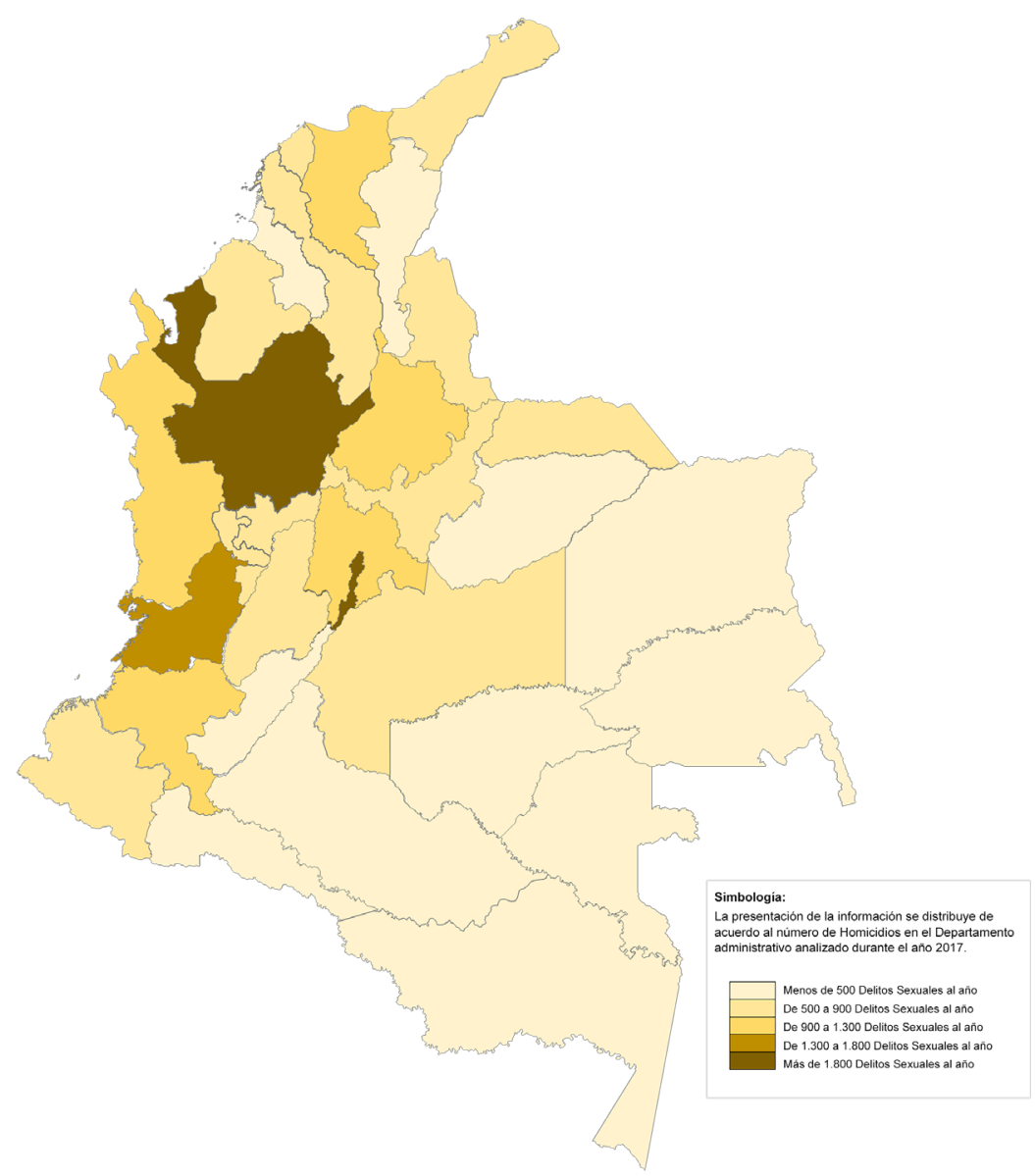

Fuente: elaboración propia basada en el Observatorio del Delito de la Policía Nacional (2017b).

El gráfico 7 denota que el sistema policial cuenta con una alta densidad de agentes activos en departamentos administrativos posicionados en la zona central del país. Asimismo, los departamentos con mayor participación económica y número de habitantes cuentan con una mayor presencia de la institución nacional encargada del orden público. En cuanto a los territorios posicionados en la parte fronteriza del país, se puede ver un menor nivel de agentes policiales debido a que, principalmente, la evidencia empírica indica que en estos doce departamentos administrativos (es decir, el 36,36 \% de los departamentos del país) solo cuentan con menos de una quinta parte de los agentes activos totales (16,43\%). Visto de otra forma, implica que un aumento en un $1 \%$ de los agentes activos en esta 
zona solo se justifica cuando el territorio fronterizo incrementa en un 2,21 \%. Por otro lado, en el caso de los territorios no fronterizos, el incremento en el área requerido es 3,87 veces menor (es decir 0,3\%) para obtener el mismo resultado.

Gráfico 7. Concentración de agentes policiales en Colombia por departamento administrativo, 2017.

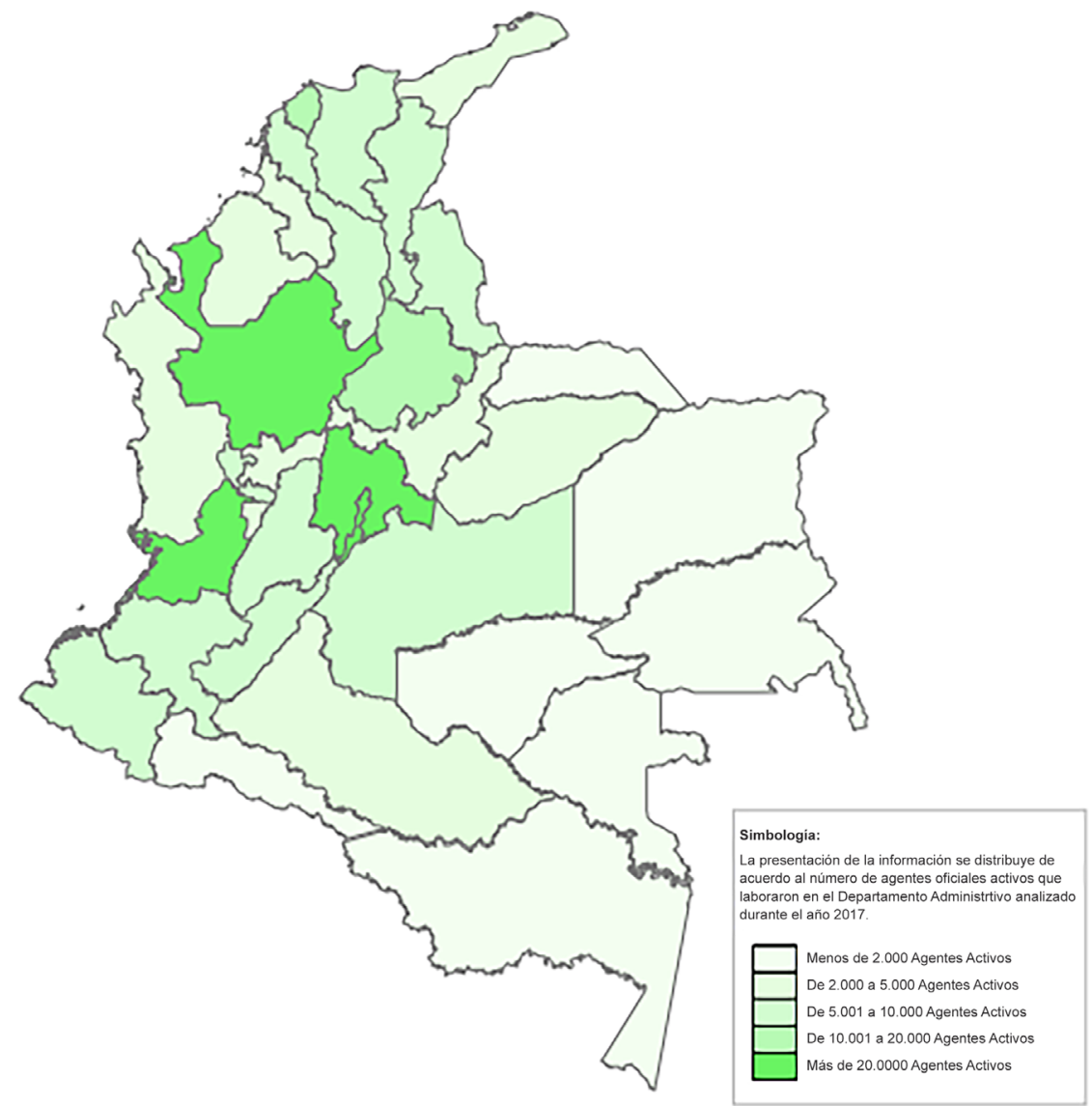

Fuente: elaboración propia basada en el Observatorio del Delito de la Policía Nacional (2017c).

El gráfico 8 expone que el número de denuncias por hurto se concentra principalmente en las ciudades en donde hay mayor logro educativo. Teniendo en cuenta la información suministrada por el portal territorial del Departamento Nacional de Planeación (TerriData), los departamentos con más de cinco mil denuncias por concepto de hurto en 2017 cuentan con al menos ocho años de escolaridad, lo cual podría dar indicios sobre una relación difusa de causalidad en doble sentido entre el acto de denunciar y el grado educativo de la población. Este hecho muestra que 
los territorios más escolarizados tienen un menor subreportel de delitos en comparación con los que presentan menor escolaridad, lo cual tiene una relación con los hallazgos de Rivera, Núñez y Villavicencio (2004) para el caso de Chile. Este aspecto es un cambio en comparación con la década anterior, cuando las regiones con más hurtos eran la región de Orinoquía y el Pacífico (Mancera, 2010). No obstante, el subreporte de los delitos, según la literatura, no depende exclusivamente del nivel de escolaridad, sino de factores que son desincentivos para la denuncia, como lo es la impunidad o la ineficiencia del sistema judicial.

\section{Gráfico 8. Concentración de denuncias por concepto de hurto en Colombia por departamento} administrativo

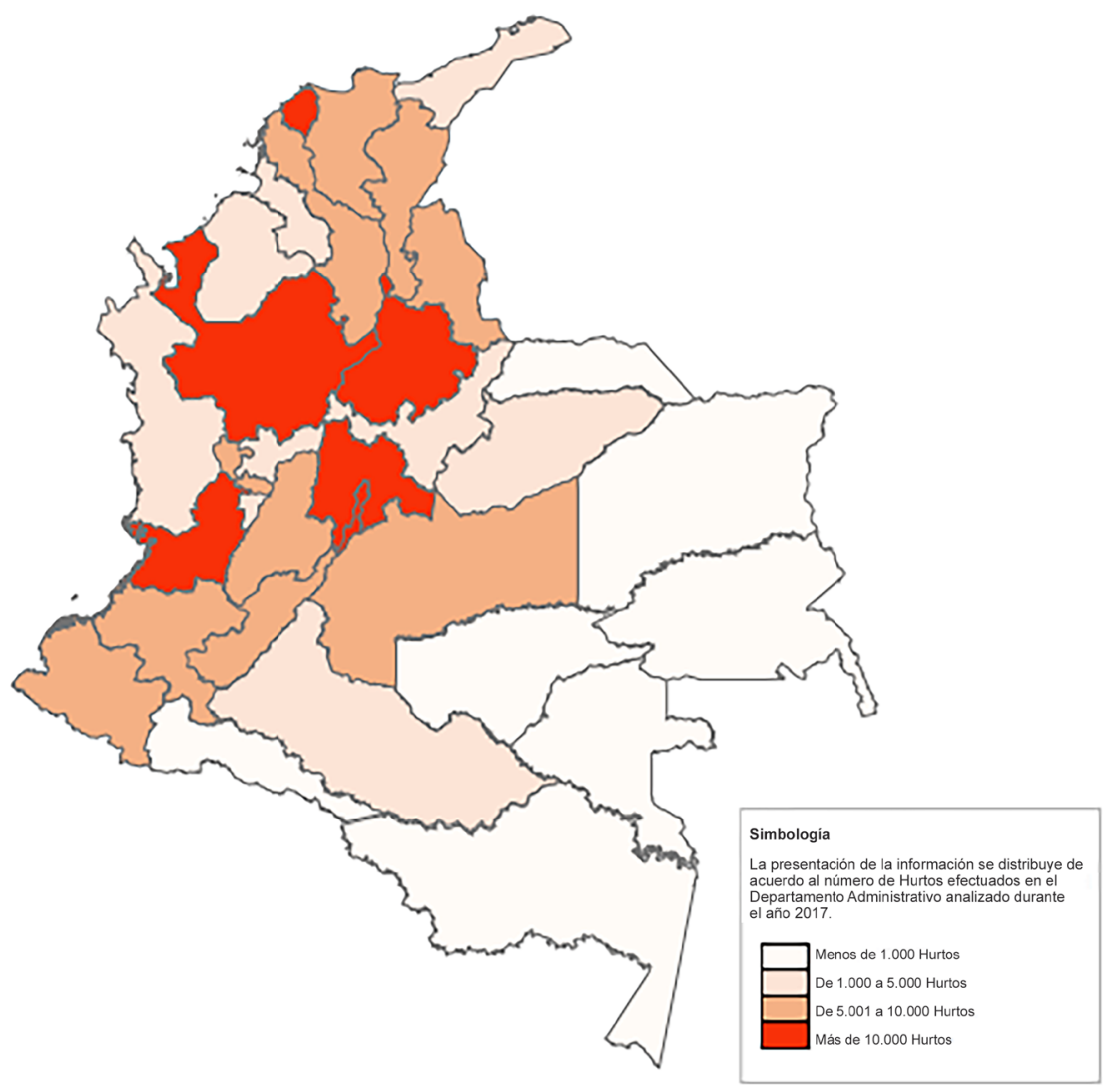

Fuente: elaboración propia basada en el Observatorio del Delito de la Policía Nacional (2017b).

En cuanto al hurto en Colombia, la BBC (2016) resalta que este tipo de delito ha sido una constante histórica. En este mismo sentido, Carrillo (2009) menciona 
que el desplazamiento forzoso ha sido uno de los principales promotores del delito contra el patrimonio privado y público en el país, puesto que la movilidad ruralurbana aumenta la concentración demográfica, dificulta la generación de ingresos y propicia las condiciones para la generación alterna de los mismos (crimen). De igual forma, Mancera (2010) corrobora que la pobreza y el desplazamiento forzado afectaban de la misma forma a distintos delitos a finales de la década anterior. Adicionalmente, Tamayo y Norza (2018) argumentan que "el hurto a personas es fenómeno principalmente urbano, cuya presencia en las zonas rurales o de menor densidad demográfica es por lo general bajo" (p. 62).

\subsection{Análisis de correlaciones, corte longitudinal y series de tiempo}

Seguidamente, se expone el gráfico de dispersión que permite determinar de manera intuitiva la presencia de relaciones entre el crimen y el PIB. A continuación, se presentan los resultados obtenidos. De lo anteriormente expuesto, el gráfico 9 revela una relación positiva definida entre el número de crímenes y la economía del departamento analizado, por lo cual es posible intuir a la luz de la evidencia empírica que los departamentos administrativos con economías más fuertes (o con mayores niveles de producción) tienen también mayores niveles de denuncias de actos criminales. Paralelamente, conforme a Delgado (2010), es preciso señalar que las comunas de la ciudad donde se concentran las tasas más altas de homicidios presentan rezagos socioeconómicos, tales como alto hacinamiento, bajo avalúo predial y composición poblacional mayoritariamente joven (dieciséis a veinticuatro años de edad).

Gráfico 9. Correlación entre número de crímenes (totales) y Producto Interno Bruto (PIB) corriente

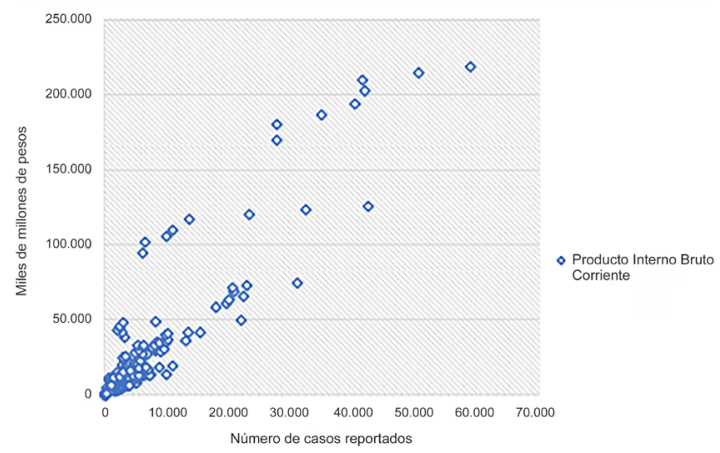

Fuente: elaboración propia basada en el Departamento Administrativo Nacional de Estadísticas (2017) y el Observatorio del Delito de la Policía Nacional (2017a). 
Ahora se va a identificar el comportamiento de las variables con el paso del tiempo. En este sentido, se hace necesario fragmentar al mismo en dos partes que permitan comparar el comportamiento entre cada uno de los departamentos y analizar el desenvolvimiento de la variable del crimen en relación con la transición de la concentración demográfica de los departamentos. Con el fin de simplificar el análisis, se seleccionaron siete departamentos del país durante ocho años para examinar las particularidades de la sección evaluada con respecto a las demás. A continuación, el gráfico 10 presenta los departamentos elegidos y su distintivo.

\section{Gráfico 10. Desenvolvimiento de los delitos sexuales en los principales departamentos}

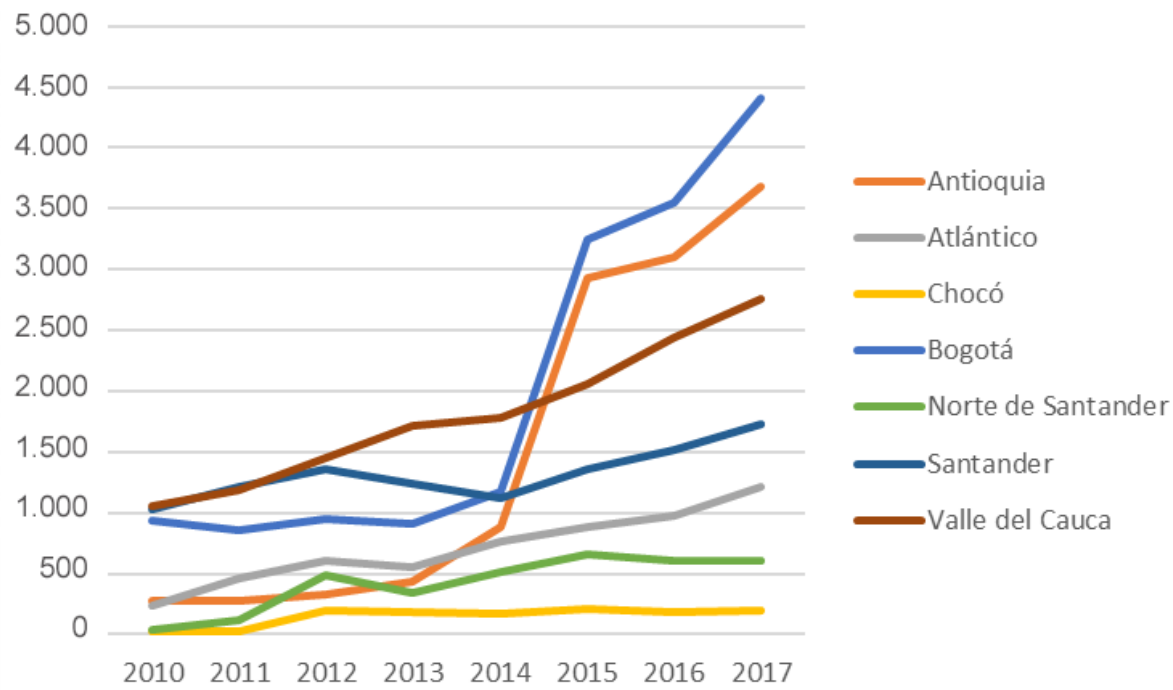

Fuente: elaboración propia basada en el Observatorio del Delito de la Policía Nacional (2017b).

Como indica el gráfico 10, la información suministrada permite identificar inicialmente una tendencia al alza. Esto quiere decir que a medida que transcurre el tiempo, el número de delitos sexuales denunciados incrementa, aunque existen departamentos como Chocó donde se mantienen casi estáticos durante todo el periodo. También hay territorios que sufrieron un drástico y persistente incremento en el número de denuncias a partir de 2015, lo cual sugiere que dichas zonas pueden haber afrontado un cambio estructural. Por ejemplo, Antioquia y Bogotá sufrieron durante el intervalo de un año un incremento aproximado de 350 \% y $235 \%$ respectivamente. En otras palabras, Antioquia presentó un crecimiento promedio anual de 2,48 veces más que el Chocó. Asimismo, en el caso de la capital el incremento medio fue 1,66 veces mayor. 
De acuerdo con el gráfico 11 se puede intuir que la mayoría de los homicidios en los principales departamentos ha sido una serie estática, por lo cual es de esperarse que el nivel permanezca más o menos constante con el paso del tiempo. Sin embargo, de las series analizadas, Antioquia, Bogotá y Valle del Cauca son los territorios con mayor número de homicidios reportados, superior a los mil hechos para los tres casos. El desenvolvimiento del crimen en estas regiones ha fluctuado de manera más marcada, pero a partir de 2012 se ha presentado una tendencia a la baja en estas tres secciones en concreto, con un decrecimiento anual de aproximadamente 4,28\%. Tamayo y Norza (2018) señalan que los homicidios en 2017 disminuyeron un $1 \%$ con diversas explicaciones, una de ellas es:

la influencia reciente del proceso de paz con las Fuerzas Armadas Revolucionarias de Colombia (Farc), acompañada de los ceses al fuego que tuvieron lugar durante la negociación entre el Gobierno Nacional y el grupo insurgente tienen un papel importante en la disminución de la violencia homicida. (Tamayo y Norza, 2018, p. 57)

Cabe resaltar que Norza y Espino (2011) mencionan que el crimen ha estado mutando de diversas maneras, en especial las bandas criminales, los casos aislados y las estructuras criminales no articuladas. Además, el ODPN menciona que lo delitos sexuales generalmente son circunstanciales y se presentan en los sitios de bajo hacinamiento.

Gráfico 11. Desenvolvimiento de los homicidios en los principales departamentos

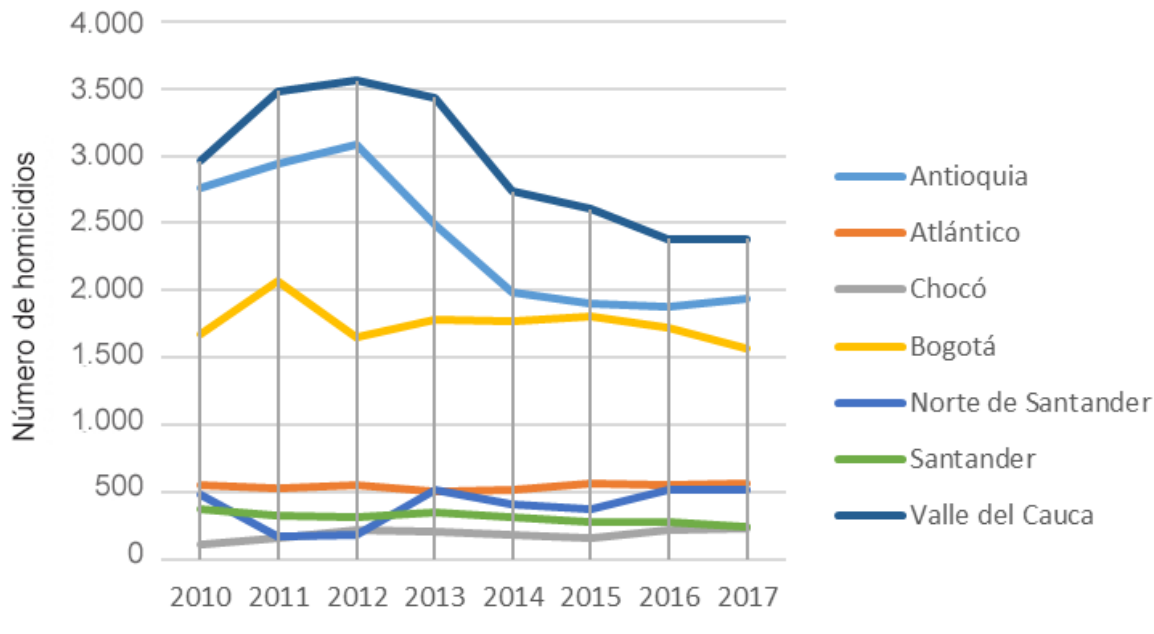

Año

Fuente: elaboración propia basada en el Observatorio del Delito de la Policía Nacional (2017d). 
Con base en el gráfico 12 se puede sugerir la existencia de una correspondencia entre el nivel de producción de un departamento y el número de denuncias de actos criminales por parte de sus habitantes. El diagrama muestra que, si bien las variaciones de estas no son idénticas con el paso del tiempo, son altamente cercanas, por lo que el desarrollo de las dos series de tiempo es aparentemente complementario.

\section{Gráfico 12. Gráfico de evolución compuesto}

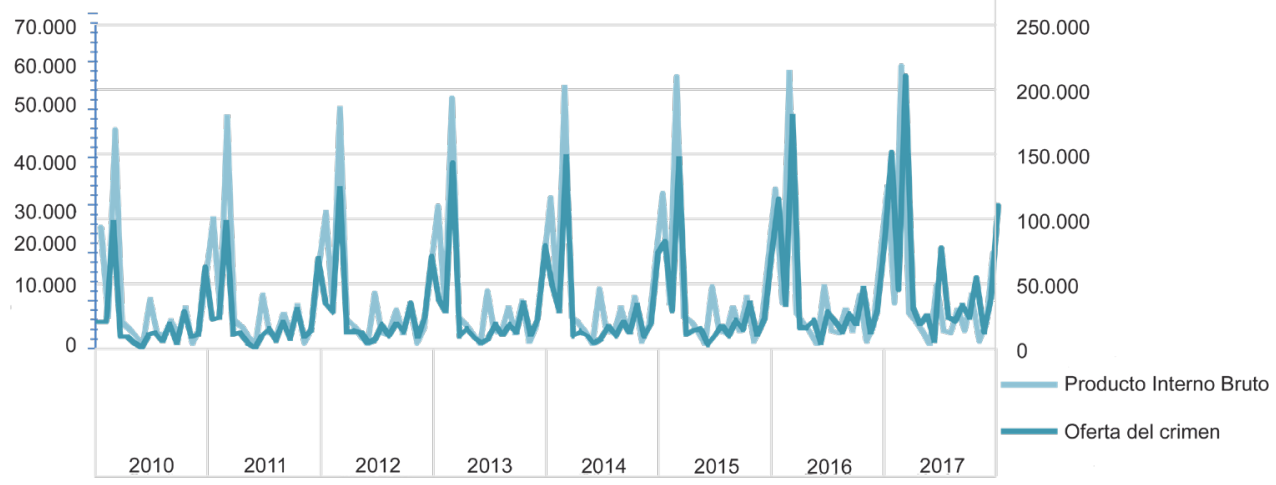

Fuente: elaboración propia basada en el Observatorio del Delito de la Policía Nacional (2017a) y el Departamento Administrativo Nacional de Estadísticas (2017).

Al analizar el gráfico 13 se puede observar una importante relación entre los niveles de denuncias en el país y las capturas. Se identifica que la eficacia empleada por la fuerza pública es disímil en cada uno de los territorios. Asimismo, se denota una marcada brecha entre estas dos variables, puesto que generalmente el número de crímenes varía en menor proporción al comportamiento de las capturas en cada uno de los territorios analizados durante los ocho años. Tamayo y Norza (2018) reconocen para el caso colombiano que

la Policía nacional ha tenido una enorme incidencia en la disminución de la criminalidad, pues, a pesar de que existen sectores en los que la mejoría es moderada, la disminución de la criminalidad derivada de la actividad policial es relevante. (p. 55)

Finalmente, Martínez (2001) presenta una concordancia con los resultados obtenidos en este estudio, ya que el método utilizado por el autor relaciona al crimen y la violencia desde una explicación teórica en donde el contexto social de cada uno de los territorios concuerda con la oferta y la demanda criminal (delitos y capturas). 
Gráfico 13. Desenvolvimiento de la oferta criminal y el número de capturas en cada uno de los departamentos de Colombia (2010-2017)

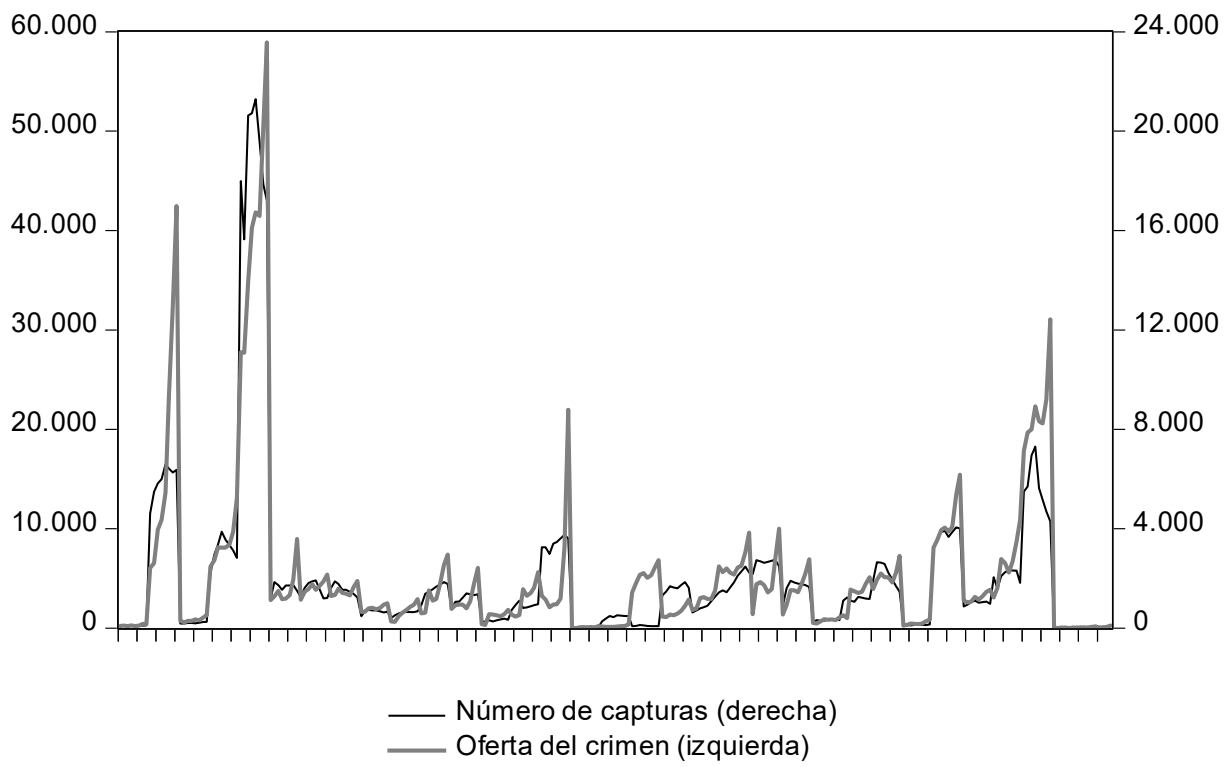

Fuente: elaboración propia basada en el Observatorio del Delito de la Policía Nacional (2017a) y el Departamento Administrativo Nacional de Estadísticas (2017).

\section{CONCLUSIONES}

El crimen y la violencia se han abordado desde dos perspectivas: como la racionalización de las personas a cometer delitos, pues todos responden a incentivos, y como la mezcla de características sociales que crean un ambiente propicio de crimen y violencia. En Colombia la decisión de tomar un enfoque de estudio ha sido difícil por las diversas condiciones de su territorio frente a los fenómenos de violencia.

Ahora bien, partiendo de las variables que usualmente son utilizadas para el estudio del crimen, se puede observar que estas responden a grandes rasgos, a la relación de crecimiento económico y criminalidad (economía del crimen), que respaldan hasta hoy lo dicho por Adam Smith: el crimen y su demanda de protección contra este están motivados por la concentración de bienes finales. Así, el presente artículo surge como aporte para futuros estudios de causalidad.

La caracterización de la oferta del crimen sugiere que el número total de denuncias que se reportan en determinada división administrativa se ve relacionado 
en un 91 \% con la fortaleza económica del departamento analizado. También se correlaciona con la densidad poblacional de este y con la disponibilidad de agentes activos proporcionados por la Policía nacional en un 76 y 84 \% respectivamente.

En lo que respecta a la dotación policial en términos de personal, esta tiene una marcada relación con la densidad poblacional $(0,83)$ y el ingreso legal esperado $(0,76)$. Además, debe recalcarse que las secciones analizadas con mayores crímenes se concentran en el centro del país, los cuales cuentan con al menos diez mil reportes al año. A la hora de hablar de homicidios, en el transcurso del periodo analizado se puede vislumbrar una tendencia a la baja desde 2012. Por el contrario, el nivel de denuncias por hurtos ha aumentado desde 2010, lo cual sugiere que el crimen en el país podría estar sufriendo una metamorfosis en cuanto a desenvolvimiento y actividades económicamente factibles.

Por otra parte, una de las limitaciones del presente trabajo recae en la composición del crimen. Esto se debe a que no es posible conocerlo a cabalidad porque la denuncia del delito es una proporción de la totalidad del mismo por el subreporte. No obstante, las denuncias pueden ofrecer una aproximación sobre el comportamiento total. Por tal razón, el uso de las denuncias como variable proxy es útil porque revela la variación y cuantía en los territorios a la par de los factores sociales y demográficos.

Finalmente, el crimen en Colombia parece haber mutado conforme a las condiciones sociodemográficas y económicas que afronta la población. Estas condiciones tienen efectos sobre el comportamiento de la criminalidad y la violencia en el país. Así las cosas, la caracterización denota que el territorio imprime condiciones para que el crimen en el país se geste de forma heterogénea, es decir, dada las características propias de cada territorio, la oferta del crimen varia en tipo y cantidad.

\section{REFERENCIAS}

Anzola, María; Iglesias, Carlos; Petrucci, Alicia; y Alvares, Gerardo (2005). Delincuencia juvenil en Paraná y su relación con las condiciones de exclusión social. En: Ciencia, Docencia y Tecnología, vol. 16, n. ${ }^{\circ}$ 31, p. 49-94.

Ávila, Ariel. (2019). Detrás de la guerra en Colombia. Bogotá: Editorial Planeta Colombiana, 529p.

Bandrés, Eduardo y Díez-Ticio, Amor (2001). Delincuencia y acción policial. Un enfoque económico. En: Revista de Economía Aplicada, vol. 9, n. 27, p. 5-33.

BBC (2016) América Latina. Redacción. Cuáles son los 6 países de América Latina que están entre los 13 con peores índices de criminalidad en el mundo, $4 \mathrm{p}$.

Becaria, Cessare (1821). Tratado de los delitos y de las penas. Madrid: D. Fermin Villalpando, 288p. 
Becker, Gary (1968). Crimen y castigo: un enfoque económico. En: Microeconomía, p. 272-297.

Buvinic, Mayra, Morrison, Andrew y Orlando, María (2005). Violencia, Crimen y desarrollo social en America Latina y el caribe. En: Papeles de población, vol. 11, n. ${ }^{\circ}$ 43, p. 167-214.

Carrillo, Anastacia (2009). El desplazamiento interno en Colombia: consecuencias humanitarias, económicas y sociales en contextos urbanos y desafios actuales. En: International Review of the Red Cross, vol. 875, n. ${ }^{\circ}$ 91, p. 527-546.

CC News (2019). América es el continente más violento y El Salvador el país más inseguro del mundo. México, 4p.

Chabat, Jorge (2010). El Estado y el crimen organizado trasnacional. En: Revista de Historia Internacional, vol. 11, n. ${ }^{\circ}$ 42, p. 3-14.

Collazos, Daniela; Fergusson, Leopoldo; La Rota, Miguel; Mejía, Daniel y Ortega, Daniel (2020). CSI in the Tropics Experimental Evidence of Improved Public Service Delivery Through Coordination. En: Documento CEDE, vol. 20. https://papers.ssrn.com/sol3/papers. cfm?abstract_id $=3629933$

Departamento Administrativo Nacional de Estadística (2017). Estadísticas, Boletín de Resultados. Cuentas Nacionales Departamentales.

Delgado, David (2010) Caracterización y determinantes de la criminalidad en Santiago de Cali 2000 a 2010. Trabajo de grado para optar por el título de Economista. Pregrado en Economía, Universidad del Valle, Colombia, 40p.

Echeverry, Juan Carlos y Partow, Zeinab (1998). Por qué la justicia no responde al crimen: el caso de la cocaína en Colombia. En: Mauricio Cárdenas y Roberto Steiner, Corrupción, Crimen y Justicia: Una Perspectiva Económica. Bogotá: Tercer Mundo, 17p.

Ehrlich, Isaac (1996). Crime, Punishment, and the Market for Offenses. En: Journal of economic perspectives, vol. 10, n. ${ }^{\circ}$ 1, p. 43-67. DOI: 10.1257/jep.10.1.43

Ehrlich, Isaac (1973). Participation in Illegitimate Activities: A Theoretical and Empirical Investigation. En: Journal of Political Economy, vol. 81, n. ${ }^{\circ}$ 3, p. 521-565.

Fajnzylber, Pablo; Lederman, Daniel y Loayza, Norman (2001). Crimen y victimizacion: una perspectiva economica. En: Crimen y Violencia en America Latina, (p. 1-63). Bogotá: Alfaomega. http://documents 1.worldbank.org/curated/en/522791468749792478/pdf/33314.pdf

Garoupa, Nuno (2003). Behavioral economic analysis of crime: A critical review. En: European Journal of Law and Economics, vol. 15, n. ${ }^{\circ}$ 1, p. 5-15.

Gaviria, Alejandro (2001). "Rendimientos Crecientes y la Evolución del Crimen Violento: el Caso Colombiano". En: Economía, Crimen y Conflicto, Bogotá, Universidad Nacional de Colombia.

López, Claudia (2016). iAdiós a las Farc! ¿Y ahora qué? Bogotá: Debate, 438p.

López, Cecilia y García, Arturo (1999). "Los costos ocultos de la paz en Colombia" En: Andrés Solimano, Felipe Sáez, Caroline Moser y Cecilia López (Editores), Ensayos sobre Paz y Desarrollo. El caso de Colombia y la experiencia internacional (81-177). Bogotá: Banco Mundial. 
Holmes, Jennifer y Gutiérrez de Piñeres, Amin (2014). Violence and the state: Lessons from Colombia. En: Small Wars E Insurgencies, vol. 25, n.², p. 372-403.

Jaitman, Laura; Caprirolo, Dino; Ochoa, Rogelio; Keefer, Philip; Leggett, Ted; Lewis, James; Mejia Jose Antonio; Melo, Marcela; Sutton, Heather y Torre, Iván (2017). Los costos del crimen y de la violencia: nueva evidencia y hallazgos en América Latina y el Caribe. Nueva York: Banco Internacional de Desarrollo. DOI: 10.18235/0000615.

Iglesias Estepa, Raquel. (2005). El crimen como objeto de investigación histórica. En: Obradorio de Historia Moderna, n. ${ }^{\circ}$ 14, p. 297-318.

Mancera, Alejandro (2010). Factores socioeconómicos y demográficos de distintas categorías de delitos en Colombia: prueba desde un panel de datos de las regiones de Colombia. En: Revista de Economía del Caribe, n. ${ }^{\circ}$ 2, p. 202-232.

Martínez, Astrid (2001). Economía, crimen y conflicto. Universidad Nacional de Colombia, 452p.

Observatorio del Delito de la Policía Nacional (2017a). Boletines anuales criminales.

Observatorio del Delito de la Policía Nacional (2017b). Estadísticas delictivas.

Observatorio del Delito de la Policía Nacional (2017c). Estadísticas de personal.

Observatorio del Delito de la Policía Nacional (2017d). Informes anuales estandarizados.

Rubio, Mauricio (1995). Crimen y crecimiento en Colombia . En: Coyuntura Economica, vol. 24, n. ${ }^{\circ} 1$, p. $101-125$.

Moser, Caroline (1999). La violencia en Colombia: Cómo construir una paz sostenible y fortalecer el capital social. Bogotá: Banco Mundial, 248p. http://documents.worldbank.org/curated/ en/248251468746671754/pdf/2159410paper.pdf\# page $=24$

Norza, Ervyn y Espino, Gloria (2011). Criminality and spatial analysis of crimes in Colombia, 2010. En: Revista Criminalidad, vol. 53, n. ${ }^{\circ}$ 1, p. 17-43.

Orellana, Liliana (2001). Estadistica Descriptiva, 64p. http://www.dm.uba.ar/materias/ estadistica_Q/2011/1/modulo\%20descriptiva.pdf

Rivera, Jorge; Núñez, Javier y Villavicencio, Xavier (2004). Crimen y disuasión: evidencia desde un modelo de ecuaciones simultáneas para las regiones de Chile. En: El trimestre económico, vol. 71, n. 284 , p. 811-846.

Ramírez de Garay, Luis David (2014). Crimen y economía: una revisión crítica de las explicaciones económicas del crimen. En: Argumentos, vol. 27, n74, p. 261-290.

Robinson, James y Urrutia, Miguel (2007). Economía colombiana del siglo XX. Un análisis cuantitativo. En: Economía, vol. 32, n. ${ }^{\circ}$ 63, p. 243-243.

Rodríguez, Antonio (2003). Los determinantes socioeconómicos del delito en España. En: Revista española de investigación criminológica, n. ${ }^{\circ}$ 1, p. 1-31.

Sánchez, Fabio y Núñez, Jairo (2001). Determinantes del crimen violento en un país altamente violento: El caso de Colombia. En: Coyuntura Económica, vol. 31, n. ${ }^{\circ} 1$ p. 92-116. 
Sarmiento, Alfredo (1999). Violencia y Equidad. En: Planeación y Desarrollo, vol. 30, n. 3, p. 47-79.

Tamayo, Fernando León y Norza, Ervyn (2018). Midiendo el crimen: cifras de criminalidad y operatividad policial en Colombia, año 2017. En: Revista Criminalidad, vol. 60, n. ${ }^{\circ}$ 3, p. 73-93. 